\title{
Comments On Matthew Mitten's "Rules Limiting Athletic Performance or Prohibiting Athletic Participation for Health Reasons: Legal and Ethical Considerations"
}

\author{
Jan Boxill \\ University of North Carolina
}

\begin{abstract}
Professor Mitten presents an interesting and well thought out discussion of whether student-athlete eligibility rules to promote good health justify limits and restrictions on the pursuit of excellence in intercollegiate sport. In his paper, he raises two concerns: 1) whether it is legal and ethical to ban the use of anabolic steroids and 2) whether it is legal and ethical to exclude an athlete from participation because of a physical abnormality. After considering all the ramifications, conflicts and apparent contradictions, and even his own development from a "novice to a mature legal scholar," Professor Mitten concludes that the NCAA has valid legal and ethical authority to establish and enforce student-eligibility rules that prohibit both the use of steroids and the participation of an athlete with a physical abnormality. I agree with his assessment and his conclusion and would like to elaborate and perhaps take the argument in a different direction. My comments will focus mainly on the first concern, and since I am not a lawyer, I will limit my comments to the ethical perspective.

As Professor Mitten points out, the NCAA's mission includes the "pursuit of excellence in both academics and athletics," and its core purpose is "to govern intercollegiate competition in a fair, safe, equitable and sportsmanlike manner." It requires that intercollegiate programs be conducted in a manner designed to protect and enhance the physical and educational well-being of student athletes. I would like to combine this with the missions of member institutions, using my home institution's mission, which is not unlike most others. The mission of the University of North Carolina is to serve all the people of the State, and indeed the nation, as a center for scholarship and creative endeavor. The University exists to teach students at all levels in an environment of research, free inquiry, and personal responsibility. Therefore, as students, they are part of the pursuit of knowledge with personal responsibility; and as athletes, this pursuit must be conducted
\end{abstract}


in a fair and safe manner. Carrying out the missions of both the NCAA and university requires special responsibilities of all of us-students, faculty, staff, administrators. Sometimes this requires some paternalistic rules; rules that limit ones autonomy for ones own good.

However, this is not unique to either sports or education; every profession has its mission and usually has a code of ethics that goes with it. What is unique is the nature of sports, and it is this uniqueness that provides for its moral significance (Boxill, 2003). Sports are artificially created activities designed for selfdevelopment. Indeed, as I have described in previous publications, at least four features of sports provide models we can use to examine the practice of sports. First sports are freely chosen, voluntary activities in which participation is an expression of the individual's creativity and his or her freedom to choose. They are designed for no ends outside themselves; they are designed for self-development. Though they may serve other purposes, sports are activities complete in themselves. Participation in sport is both conscious and free, and the participants know and freely accept the rules. This voluntary co-operation is required to begin, continue, and end the activity.

Second, sports are rule-governed; there are at least two types of rules: regulative and constitutive. These rules include the creation of artificial obstacles to physically challenge the participants. Some sports have more rules than others, and some may have only one sort. Regulative rules are rules of decency, safety, and fair play. There are many rules for decency and safety, and when they are violated, players are penalized. Rules of decency reflect basic moral standards, for example, fighting and biting. Rules of fair play include penalties for moves of strategy within the game. The basic ground rules are accepted, and they might be manipulated for strategy, but within limits. For example, in basketball when a player is fouled and cannot continue to play, the rules allow another player to be substituted to shoot the foul shot. Of course, you put in the best free throw shooter on the bench. This is fair; but if a player feigns injury to get a better shooter in, this violates the rules of fair play.

Added to the rules of decency and fair play are constitutive rules that define the game and the permissible moves. Their existence comes from their acceptance. Constitutive rules define the activity and provide for the development and display of distinct sets of skills and talents. In combination, these rules impose a discipline and create a framework for self-expression and self-development. These rules require calculations, decisions, strategies, and mental agility, as well as a physical challenge. Thus, when I agree to play basketball, I agree first to abide by the rules that define the game, and the rules of decency, safety, and fair play within the game. Further, I use these rules as a disciplined means of self-expression, self-development, and self-respect. In playing basketball, for example, I cannot put the ball in the basket any way I choose. I must put it in the basket in the ways the rules permit. I cannot stand on a ladder, knock someone out of my way, or climb on someone to reach the basket. Nor can I score a basket by sending the ball through the bottom of the net. To be sure, these attempts use some skill and ingenuity, but the rules impose a kind of discipline that requires me to devise ways of scoring a basket that require skill, bodily excellence, and ingenuity. The rules force me to use various strategies to create moves to score within these carefully specified rules. 
The third feature of sport is that it is physically challenging. The rules that define the sport activity are specifically designed for displaying and expressing bodily performance and aimed at bodily excellence. Thus, these rules often create artificial obstacles for just this purpose. Further, often rule changes are made for just this purpose. Without these rules, no particular bodily perfection would necessarily be exhibited.

The final feature of sport is that it requires competition. Moreover, it is in competition that the mental and physical skills, talents, and coordination come together. It is as Robert Simon put it, "a mutual challenge to achieve excellence" (Simon, 2004, p. 24). This feature of sport dramatizes the morality of a community in competition. Competition as a challenge to better oneself is valuable to both society and to the individual. This is not unique to sport situations; it is important in all fields of endeavor. Competition is valuable when it is viewed as a cooperative challenge and not as combat, in which the purpose is to destroy the opponent. In these ways competition serves to develop citizens, as well as individuals.

There are, of course, aberrations, and these aberrations are definitely dramatized in a sport context. This is especially clear when competition is viewed as combat, emphasizing the "win-at-all-costs" syndrome, and when viewed as a zero-sum game. It has been argued that these are essential features of competition. However, if my analysis is correct, these "features" are not essential to the notion of competition and are, as I have noted above, aberrations.

The point of competition is not just to win, but to function at a maximum, to develop oneself to the fullest, and to do this one must compete against those who challenge. Certainly winning is part of the game (i.e., someone must win), but one does not see an opponent as an enemy to be defeated, but one whose excellences challenge and make possible one's own best performance.

Now of course this is an ideal of sport, so it is not surprising that the practice falls short. Nevertheless, this ideal does provide us insight into why or where the practice deviates from the model. It also provides justification for governing bodies to enforce the rules.

So let me return to the discussion of performance-enhancing drugs. Why would anyone take them? Here are some responses from my class in Ethics in Sports: You can't win without them; you need them to compete with those taking them; it is part of the competitive spirit; you feel insecure without them; increases the level of competition; allows you to be a the top of their game; can't perform as well without them; a need to be better than others; to gain an advantage; gives you an edge; to win-it gives you confidence to achieve a goal; the fame and fortune that comes with winning and being successful; pressure from teammates and coaches; an attempt to reach the pinnacle of performance. These responses reveal some interesting insights, some of which actually fit within the model of sport given. If you are trying to achieve excellence or reach the pinnacle of performance, then you want to do that which promotes or enhances your performance. Now this includes good equipment, good nutrition, good training, etc., all of which are permitted. But why limit the enhancements to these? Why not other enhancements, which are thought truly to allow you to reach the pinnacle? This is parallel to achieving excellence in education - and we could add here some other "enhancements"-caffeine, Ritalin, aderall, marijuana. Do we prohibit them for students? 
If we truly want to reach the pinnacle, then why not allow all kinds of enhancement? Why prohibit certain performance enhancing drugs such as steroids? How can rules prohibiting the use of these drugs be defended? Many arguments have been offered in the literature, and I think the best philosophical discussion of the issue is found in Chapter 4 of Robert Simon's (2004) book, Fair Play. The arguments fall into three categories:

1. They are harmful to the athletes taking them.

2. They are harmful to other athletes-including coercing others into using them.

3. They harm sport itself - the integrity and nature of sport, which requires fair play and respect for persons.

Let's look briefly at each.

Performance-enhancing drugs may indeed harm the user. But what if the athlete fully consents to this harm? But do they "fully consent"? Are they fully informed? What harms are there? As Professor Mitten points out, "there are no definitive scientific or epidemiological studies of . . . serious health effects." Further, aren't we just being paternalistic? Isn't it my right to take these if I want to? After all, there are many other things in sports that are harmful to ones health as well. Football hits and other plays are clearly harmful. Rules exist to reduce the harm, but football itself is an arena of harm. It's not surprising many schools ban it, and if President Roosevelt had not stepped in, we likely wouldn't be seeing it today!

What about coercion? Are athletes really free not to use steroids? Given the comments of my students, it seems the answer might be "No," not if they want to perform at the highest levels. This forces athletes to consent to things they would not otherwise consent to-which is coercion. But is all coercion wrong? We coerce athletes into training hard, doing schoolwork. Is this coercion, or is it just the pressures relating to any aspect of life? How do we distinguish those which seem acceptable from those that we might think are unacceptable? One way to distinguish between them is that unacceptable ones are those we would not consent to. No doubt, football can be harmful to the health of athletes, but we have devised equipment and added rules to reduce that harm so that the game can be played. We can't eliminate all the harm, but we can reduce it. So we consent to what is necessary for our protection in football. But what we wouldn't do is add something that would add to the harm, which if any of our analyses were correct, steroids would do just that. Therefore, it seems the NCAA is justified in prohibiting steroids to protect athletes from being placed in a situation in which they have to decide whether to take on an added risk.

With regard to harm to the sport, fair play, and respect for persons, often it is said that drugs reduce the challenge of sports to the achievement of drugs and pills rather than skill. Are they more akin to cork bats, or to better facilities, equipment, and coaching? Drugs don't eliminate the need for all hard work; they just enhance this hard work by allowing your muscles to recover and take on more. At a meeting of coaches in Colorado Springs several years ago, former NFL All-pro Steve Corsin gave a talk about his steroid use. He had taken steroids most of his NFL career, and although he was wearing a beeper because he was on a waiting list for a heart transplant (a direct result of the use of steroids), the first question coming from a high school coach was, "how can I get some of the stuff?" He completely 
overlooked the danger of using the drugs; rather he saw the drugs as a means for making winning players of his young men. And why not?

Ours is a "steroid nation." We promote "bigger, stronger, faster" —not just the movie of that name (Aarnio, et al., 2008), but in nearly every aspect of our society. We praise those who are the best - the biggest, the fastest, the strongest, the richest, and, much to our detriment, we usually don't care how they got there. As the movie says, "We define ourselves in superlatives," We are the biggest, strongest, fastest country in the world, so it should come as no surprise that we have developed a "win at all costs" culture and mentality. Sadly, we have allowed this to happen. If so many people cheat to win, how can honest people be expected to play by the rules and not be at a disadvantage - in school, work, sports, business?

We criticize this mentality in sports, but it doesn't occur only in sports. The present financial crisis shows the results of this mentality. Nevertheless, we can learn a great deal from sports because, as I have discussed in other papers, sport is a microcosm of society, but it is also more than that (Boxill, p. 9). Sports reflect and mirror society, but they also affect society like no other activity. Sport promotes the idea that everyone wants to be a winner, to be bigger, faster, stronger; these are the ones who are praised. It is also the case, however, that when you choose to participate in a voluntary activity such as collegiate sports, you also choose what goes along with it. You have chosen to be a representative of the university, and as such, you have chosen to be in a public arena that broadens your influence on others. The university must also uphold this status and their mission. The win at all costs mentality must be curtailed, especially in sports, because it is dramatized in sports. This affects society; we see how the win at all costs mentality achieves success in sports, so why not in society? Drug use is seen as necessary to win, and so in a win at all costs mindset, drugs seem justified. As a consequence, people think that since everyone is doing it, they should too. But it is up to the governing bodies of sports at educational institutions to be courageous and do what is best for students, athletes, sports, and education. The first step in changing the win at all costs mentality is to prohibit the use of steroids.

Sports are artificially created activities designed for self-development, selfesteem, and self-respect. Participants are partners in a challenge to achieve excellence, not enemies to be defeated by any means necessary. We must treat opponents as persons rather than as objects. Seeing people as objects, as things, allows you to treat them in any way you want. There is no ethics between people and things, only between people and other sentient beings. The key is respect, something we all desire. We have promoted the misconception that respect means being the best-the richest, strongest, fastest. But that isn't the basis of respect. Respect comes from treating others as partners, as people with dignity, who have desires and aims of their own that they want to be able to develop. This requires reciprocity and community. How do we know when we fail to treat others with respect? We do so when we deceive others into doing things they would not consent to, or when we manipulate or coerce others to promote our own ends. Can we depend on the participants to learn this on their own? Perhaps, but it is the duty of the university and the NCAA to promote respect by prohibiting the use of drugs. It becomes part of the rules, and, as stated above, when one chooses to participate, one chooses to abide by the rules by which the game is played. That is how respect is maintained not only for the participants but also for the game. 
The theme of the conference is the health of athletes; their health is connected to the health of sports and the university. It is our ethical duty to respect these because the death of ethics is the sabotage of excellence.

\section{References}

Aarnio, T.J., Schiffrin, R., \& Weiser, R. (Executive Producers); Buono, A., Rawady, T., \& Czarnecki, J. (Producers); Bell, C., Buono, A., \& Rawady, T. (Screenwriters); Bell, C. (Director). (2008). Bigger, Stronger, Faster (film). New York and Austin: Magnolia Studios.

Boxill, J. (2003). The moral significance of sport. In J. Boxill (Ed.), Sports ethics: An anthology (pp. 1-12). London: Blackwell.

Simon, R.L. (2004). Fair play: The ethics of sport (2nd ed.). Oxford: Westview Press. 